\title{
The Slovak experience with local-national fora - overview of the framework and process description
}

\author{
T. Duranova \\ VUJE, a.s., Okruzna 5, 91864 Trnava, Slovak Republic.
}

\begin{abstract}
The complexity of the emergency preparedness and post-accident management was recognised and analysed in depth as well as relations among different stakeholders, and their roles and tasks within the post-accident preparedness process. Each stakeholder defined its specific role and work, and forms a part of the complex system; each stakeholder defined where and how to be involved in the whole system. Recovery was defined in the Slovak legislation by one general word before the process of the post-accident preparedness started. The process revealed the recovery issues and started the discussion in depth. Communication between different stakeholders involved in the active work of the Slovak stakeholder panel at facilitated workshops, seminars, workshops, training courses and exercises was found to be very important to get a balanced view on various aspects of the issues at stake at the national, regional and local levels. It enabled a common language and a shared understanding of the challenges to be developed.
\end{abstract}

Keywords: stakeholder involvement / post-accident / preparedness / framework process / Slovakia

\section{Introduction}

Slovakia was impacted by the Chernobyl accident, and with four nuclear reactors generating half of its electricity and two more under construction, the country has an interest in improvement and strengthening of the nuclear emergency preparedness and recovery management.

The main goal of the activities undertaken under the NERIS-TP Project in the area of stakeholder engagement in Slovakia was to improve and strengthen the emergency and post-accident preparedness and recovery management at all levels: national, regional and local.

The main interest and motivation for this activity is to share experience about different initiatives on emergency and rehabilitation preparedness and management throughout Europe and to develop and apply methods and models of stakeholder engagement and participation to allow and support dialogue.

The model for stakeholder engagement and participation included the following: testing, customisation and use of models and tools; case studies using scenarios developed; building a network and trust between partners within the Slovak Republic and within Europe through EC projects; facilitated workshops, exercises, seminars and training courses; establishing the Slovak panel and EURANOS Handbooks User Group; and participation in the network involved in development of the EURANOS Handbooks for assisting in the management of contaminated inhabited areas, food production systems and drinking water.
The post-accident preparedness process in Slovakia was initiated by the active participation of stakeholders in the EVATECH project co-funded by the EC, VUJE and NRA SR (2003), and continued within the activities of the EC EURANOS and NERIS-TP projects supported by national projects (Nisbet et al., 2010a, 2010b).

\section{Context and characterisation of the Slovak process}

The specific issues considered in the post-accident management preparedness process under the research projects mentioned above are the following:

- management of contaminated inhabited areas,

- management of contaminated food production systems,

- management of drinking water supply,

- withdrawal of emergency countermeasures,

- rehabilitation of living conditions in the contaminated areas,

- organisation of public authorities,

- stakeholder involvement,

- communication,

- post-accident policy, and

- evaluation tools and methods for supporting the management team.

The process for post-accident preparedness in the Slovak Republic (SR) involved a large group of actors at the national, 
regional and local levels. The expertise resources mobilised in this process included the Nuclear Regulatory Authority of the SR, Public Health Authority of the SR, Crisis Management and State Safety Office, SR Government Office, Ministries and national administrations concerned with post-accident issues, public and private expert institutes, universities in the field of nuclear safety and radiation protection, Regional Civil Protection and Crisis Management Offices, Mayors of villages and representatives of Municipality Crisis Staff (members of GMF - Group of European Municipalities with Nuclear Facilities), national Association of Municipalities and local/regional Civic Information Commissions (Dolny Lopašov, Madunice, Kalna nad Hronom and others), Regional Public Health Authorities, Regional Veterinary and Food Administration, Slovak Head Office of the Radiation Monitoring Network (SURMS), Slovak Hydrometeorological Institute (SHMU), Slovak Army (RCHBO), Slovak NPPs (Emergency planning and preparedness units and Headquarters), and Fire and Rescue brigade.

About 60 people took part in the work at the facilitated workshops, seminars and exercises developing the tools and cooperation practices and habits, and forming a post-accident community.

Several modelling and calculation tools, but also guidance and handbooks, were used by stakeholder panels for facilitating discussions with national, regional and local actors on post-accident issues. These tools included:

- the RODOS/JRodos complex Decision Support System customised to the Slovak Republic conditions (LSMC modules, FDMT, ERMIN, AgriCP modules and others),

- the national decision support system RTARC (VUJE, Inc.),

- the EURANOS Handbooks for assisting in the management of contaminated inhabited areas, food production systems and drinking water, and

- Web-HIPRE (HIerarchical PREference analysis in the World Wide Web) software for structuring decision analytic problems using multi-criteria evaluation and prioritisation with an integrated module allowing the import of ESY files (RODOS output files), which contain a selection of appropriate alternatives and attributes.

All actors from national/regional/local levels had access to the expertise of VUJE employees participating in the development of RODOS modules, Handbooks and Web-HIPRE tools. These models and tools were demonstrated to all actors on several occasions.

\section{Main achievements}

The main achievement in the area of the post-accident management preparedness process was the development and customisation of the EURANOS Handbooks for assisting in the management of contaminated inhabited areas, food production systems and drinking water, and their incorporation into the JRodos Decision Support System modules (ERMIN2 and AgriCP) with the active participation of a wide range of stakeholders from the Slovak Republic. Through this development and active participation of all stakeholders, changes in the off-site emergency plan development took place. Under the Decree of the Ministry of the Interior No. 533/2006 on details concerning public protection against the effects of dangerous materials, Attachment 3, Chapter A, point 2, letter c) the text and graphic part of the plans and countermeasures have to be completed with tasks on recovery of the contaminated area and food chain. The recommendations and worked out examples based on the Handbooks were developed and provided to the county and district offices. They were used and implemented by some of them. To make the process sustainable there is a need to give the Handbooks the status of official national documents as a basis for their use by the wider community of specialists and organisations related to emergency preparedness.

The facilitated workshops driven by exercise scenarios using the tools developed formed good conditions for continuation and should be used in the institutional preparedness process in the future.

The motivation and involvement in the process of the selfgovernment representatives from the Municipality Crisis Staff who are members of the GMF and national Association of $\mathrm{Mu}-$ nicipalities and local/regional Civic Information Commissions (Bohunice and Mochovce NPPs territory) is the key element for future development in the area of emergency preparedness and recovery management.

The local communities and private actors have an institutional role in the emergency preparedness process. For municipalities within the emergency planning zone of nuclear facilities, their Crisis Staff have to prepare Community Safety Plans, including nuclear issues. Even businesses are included in the organisation of emergency planning and management for all types of risks, including nuclear.

The preparedness process for post-accident recovery is based mainly on the research activities mentioned above, which were later implemented in the legal and regulatory framework as requirements. The legislation basis as well as the regulatory framework is in the process of improvement and needs more precise development of regulations and guidance. These requirements came as a result of the recommendations from the research projects. The precise evaluation of the process is given in the last part of the present article.

\section{Results of the process and impact on the legal framework}

The process revealed the post-accident and recovery issues and started the discussion in depth, which contributed significantly to changing the patterns of relations between the stakeholders involved. Continuous and systematic development and stakeholder cooperation is necessary in the future, especially between national and local dimensions. The complex national post-accident policy needs to be improved, and further development of the National Emergency Plan should contribute to better clarification of roles, cooperation, co-framing of the issues and the impact on the legal framework. The process initiated changes in the off-site emergency plans, and an adaptation of the EURANOS Handbooks within the off-site emergency planning took place to some extent. Recommendations and worked out examples based on the Handbooks for assisting in the management of contaminated inhabited areas, food production systems and drinking water were developed by 
the Section of Crisis Management and Civil Protection of the Ministry of the Interior of the SR. They have been provided to the county and district offices, but have no official status yet. To make the process sustainable there is a need to give the Handbooks the status of official national documents as a basis for their use by the wider community of specialists and organisations involved in emergency preparedness. Professionals and members of the administrative bodies see the methods of post-accident planning and preparedness in their sections and departments in connection to the emergency preparedness and post-accident management, but they are unsuccessful in promoting politics of complex emergency preparedness and recovery at the upper level of the Ministries, Authorities and Government. At the local level, self-government and Municipality Crisis Staff are not sufficiently prepared due to the frequent personal changes after all elections and missing efficient mechanisms from the national and regional authorities and Crisis Management Offices. Particular activities (workshops, exercises, training courses) were evaluated at particular Ministries and national administration, but were not a subject of the complex evaluation of the emergency preparedness. There were no tasks and recommendations delivered which would provide a systematic approach to the post-accident management and preparedness process, and a national post-accident policy was not defined.

The development of a National Emergency Plan as well as the reactivation of the technical operations management group (ORS), the professional body of the Central Crisis Staff, is a key issue. A detailed legal or regulatory framework in the area of post-accident management and recovery is missing.

The Slovak stakeholder panels have shown that they are able to work together, to communicate problems, and to absorb newcomers into the working groups. Working in the form of facilitated workshops with scenarios developed using customised operational tools (RODOS/JRodos, RTARC,
Web-HIPRE) makes work more efficient, and focuses on possible real problems and finding real solutions. Communication between different stakeholders was found to be very important to get a balanced view on various aspects of the issues at stake at the national, regional or local levels. It enabled a common language and a shared understanding of the challenges to be developed. There is a common understanding of the necessity of continuing joint stakeholder meetings and annual workshops for sharing experiences, identifying gaps and improving preparedness. We should engage more stakeholders in the process and bring more clarity to the roles and responsibilities at each level, and identify the need for improvement with regard to cooperation along the chain national-regionallocal/municipality.

\section{References}

Nisbet A.F., Brown J., Howard B.J., Beresford N.A., Ollagnon H., Turcanu C., Camps J., Andersson K., Rantavaara A., Ikäheimonen T., Duranova T., Oughton D., Kirchner G., Papachristodoulou C., Ioannides K., Kwakman P. (2010a) Decision aiding handbooks for managing contaminated food production systems, drinking water and inhabited areas in Europe. In: Enhancing Nuclear and Radiological Emergency Management and Rehabilitation, Key Results of the EURANOS European Project (W. Raskob, M. Hugon, Eds.), Radioprotection 45 (5), S23-S37.

Nisbet A.F., Andersson K. G., Duranova T. (2010b) Demonstration of generic handbooks for assisting in the management of contaminated food production systems and inhabited areas in Europe. In: Enhancing Nuclear and Radiological Emergency Management and Rehabilitation, Key Results of the EURANOS European Project (W. Raskob, M. Hugon, Eds.), Radioprotection 45 (5), S243-S249. 